\title{
LA PROFESIÓN DE FE DE ROUSSEAU
}

\author{
POR \\ MARÍA JOSÉ VILLAVERDE RICO ${ }^{1}$ \\ Universidad Complutense de Madrid
}

\section{RESUMEN}

Rousseau ha sido considerado un protestante cercano a los sectores calvinistas más liberales y próximo al socinianismo, así como uno de los grandes defensores de la tolerancia y de la libertad de conciencia. Sin embargo, si analizamos más en profundidad sus obras, encontraremos inquietantes notas de intolerancia con respecto a los ateos, a los católicos y a las mujeres en general, que dificultan encuadrarle entre los autores más tolerantes de su época.

PALABRAS CLAVE: calvinismo; tolerancia; libertad de conciencia; profesión de fe.

\section{ROUSSEAU'S PROFESSION OF FAITH}

\author{
ABSTRACT \\ 137-146. https://doi.org/10.3989/hs.2018.013 \\ Recibido/Received 09-05-2017 \\ Aceptado/Accepted $\quad 09-06-2017$
}

Traditionally, Rousseau has been regarded as a Protestant thinker close to the most liberal Calvinist sectors as well as Socinianism, and also as one of the most vigorous defenders of tolerance and freedom of conscience. However, an in-depth analysis of his works reveals disturbing streaks of intolerance towards atheists, Catholics and women, all of which cast doubt on his standing among the most tolerant authors of this time.

KEY WORDS: Calvinism; Toleration; Freedom of conscience; Profession of faith.

Cómo CITAR ESTE ARTículo / CITATION: Villaverde Rico, M. a J. 2018. «La profesión de fe de Rousseau». Hispania Sacra 70, 141:

\section{LA POSICIÓN DE ROUSSEAU ANTE LA RELIGIÓN: DE LAS DUDAS A SU CRUZADA EN FAVOR DE LA PROVIDENCIA}

La concepción de religión de Rousseau aparece expuesta en varias de sus obras como las Lettres morales (también conocidas como Lettres à Sophie), la llamada Lettre à Voltaire sur la Providence, la Lettre à Christophe de Beaumont (el arzobispo de París, a quien le recrimina amargamente su decreto de condena de Emile)², la llamada "Profesión de fe del Vicario saboyano", que forma parte de Emile, las Lettres

1 majovi2@gmail.com / ORCID iD: http://orcid.org/0000-00023116-4820

2 El Mandement del arzobispo de París está fechado el 20 de agosto de 1762 y fue publicado el 28. Pero ya a comienzos de junio la policía de París se había incautado del libro y el 9 de junio el Parlamento de París había ordenado que el libro fuera quemado en el patio del palacio del Parlamento. Por supuesto se había prohibido su venta y ordenado a quienes tuviesen algún ejemplar entregarlo. También se había decretado prisión para Rousseau. Rousseau 1969a: CLIXX-CLXX. écrites de la Montagne y la Lettre à M. de Franquières, entre otras. Todo este conjunto de escritos aporta datos relevantes para caracterizar su posición sobre la religión. A ellos hay que añadir el penúltimo capítulo de El contrato social, titulado "De la religión civil»" un capítulo largo e importante que cierra el bucle de lo que es la exposición de sus ideas religiosas.

Si al análisis de dichas publicaciones sumamos su biografía, que desvela sucesos que pueden ayudar a comprender mejor su pensamiento religioso, el puzzle estará armado. Empecemos, pues, con una breve nota

3 Du contract social dedica el capítulo penúltimo de la obra a hablar "Sobre la religión civil». El título del capítulo puede inducir a engaño pues los dogmas de la profesión de fe, que tienen que acatar obligatoriamente todos los ciudadanos, son de carácter religioso. Tan solo uno de ellos, la santidad del contrato social y de las leyes, tiene carácter civil. Ello no significa, sin embargo, que el título carezca de sentido pues el objetivo de Rousseau era el de establecer una religión «civil» reducida a los mínimos preceptos religiosos. 
biográfica. Es un hecho que Rousseau, un autodidacta que se fue formando a lo largo de su vida de manera anárquica y asistemática ${ }^{4}$, vivió, a su regreso a París en 1744 (después de su interludio veneciano), una experiencia que le marcó profundamente, su relación con Diderot, Grimm y algunos otros ilustrados. ${ }^{5}$ Así expresa sus vivencias en las Rêveries:

Je vivais alors avec des philosophes modernes [...] ils avaient ébranlé toutes les certitudes que je croyais avoir sur les points qu'il m'importait plus de connaître [...] ardens missionnaires d'athéisme [...] jamais je n'adoptai leur désolante doctrine. ${ }^{6}$

Fue sobre todo Diderot, ese amigo reconvertido más tarde en enemigo ${ }^{7}$, quien más le influyó. El camino emprendido por el enciclopedista hacia el materialismo y el ateísmo, que se inicia con la Lettre sur les aveugles, publicada en 1749, y con las Pensées sur l'interprétation de la nature, de 1753, desestabilizó profundamente a Rousseau: «Je consultai les philosophes, je feuilletai leurs livres, j'examinai leurs diverses opinions [...] Les écouter n'étoit pas le moyen de sortir de mon incertitude». ${ }^{8}$

Como se deduce de las Rêveries ${ }^{9}$, de las Lettres morales $y$ de la Lettre à $M$. de Franquières, Rousseau era un creyente impregnado de profundas convicciones religiosas, cuya amistad con Diderot arrasó con todas sus creencias y le dejó sin recursos para sustituirlas. ${ }^{10}$ Se describe a sí mismo como un barco a la deriva ${ }^{11}$, perdido en un laberinto ${ }^{12}$ de dudas, angustia y ansiedad del que tardó años en liberarse:

Dans ce dedale immense des raisonnemens humains [...] vous vous perdrez dans les subtilités metaphisiques, les perplexités de la philosophie vous assiégeront de toutes parts, vous verrez par tout des objections et des doutes, et à forcé de vous instruiré vous finirez par ne rien savoir. ${ }^{13}$

Tocado anímicamente, inmerso en una inseguridad que le afligía y le desgarraba ${ }^{14}$, Rousseau no se sentía capaz de superar esa etapa mediante el razonamiento. Pero tampoco podía vivir sin creer ni soportaba el incesante dudar del escéptico. ${ }^{15}$ Como escribe el 15 de enero de 1769 a M. de

4 Como Rousseau confiesa en su obra autobiográfica, el inicio de su formación se debió a Mme. de Warens, quien le recogió con 16 años después de su marcha de Ginebra.

5 Rousseau fue asiduo durante un tiempo de El Panier Fleuri, el restaurante donde se codeaba con la flor y nata de la côterie ilustrada.

6 Rousseau 1967a: 511.

7 Fabre 1961: 155-213.

8 Rousseau 1969a: 568.

9 Rousseau 1967a: 512.

10 En su Introducción a las Lettres morales y otras obras sobre lo que denomina «Dios y la Revelación», H. Gouhier sostiene que Rousseau no quería sentirse desarmado intelectualmente ante el ateísmo y escepticismo de sus amigos y que su conciencia le exigía verificar las verdades que su corazón le dictaba. Rousseau 1969a: CXC.

11 Rousseau 1967a: 512.

12 «Laberinto» es una de las palabras que repite una y otra vez. Ver ídem.

13 Rousseau 1969a: 1087.

14 «Je perdois chaque jour quelqu'une des opinions que j'avois receues [...] je sentis peu-à-peu s'obscurcir dans mon esprit l'évidence des principes». Rousseau 1969a: 567.

15 «Le doute sur les choses qu'il nous importe de connoître est un état trop violent pour l'esprit humain; il n'y résiste pas longtems, il se décide malgré lui de manière ou d'autre, et il aime mieux se tromper que ne rien croire». Rousseau 1969a: 568.
Franquières (paradigma del escéptico que se mantiene en el escepticismo), en la etapa transcurrida entre 1757 y 1762 examinó todos los sistemas filosófico-religiosos y se decidió por el que le ofrecía menos dudas: «il falloit me résoudre à rester sans rien croire, comme vous faites [...] ou croire comme j'ai fait». ${ }^{16}$

Su esfuerzo por pasar revista a todos los sistemas filosóficos y fijar de una vez su doctrina ha sido comparado por algunos estudiosos como Henri Gouhier o posteriormente Sébastien Charles con el método de Descartes para trascender el escepticismo. ${ }^{17}$

Finalmente, tras largos años de titubeos, Jean-Jacques fue capaz de vencer ese estado de incertidumbre y de vacilaciones y romper con el grupo de filósofos ateos y materialistas. Como escribe a la marquesa de Créqui en 1761: «me he desligado completamente del partido de los filósofos. No me gusta que se predique la impiedad ». ${ }^{18}$ Acabó así reconciliándose con el credo religioso que le habían inculcado desde su infancia ${ }^{19}$ : "J'ai cru dans mon enfance par autorité, dans ma jeunesse par sentiment, dans mon âge mûr par raison; maintenant je crois parce que j'ai toujours cru». ${ }^{20}$

Aceptaba así las concepciones religiosas que le resultaban más consoladoras. Así lo reconoce en su respuesta a Voltaire quien, a raíz del terremoto de Lisboa, había expuesto sus dudas sobre la existencia de Dios en su llamado Poema contra la Providencia: "parce que croire et ne croire pas, sont les choses qui dépendent le moins de moi, que l'état de doute est un état trop violent pour mon âme [...] qu'enfin mille sujets de préferance m'attirent du côté le plus consolant». ${ }^{21}$

Como relata en la «Profesión de fe del Vicario saboyano», su sentimiento interior le conducía irremediablemente hacia la creencia en Dios:

J'ai trop souffert en cette vie pour ne pas attendre une autre. Toutes les subtilités de la Métaphysique ne me feront pas douter un moment de l'immortalité de l'ame, et d'une Providence bienfaisante. Je la sens, je la crois, je la veux, je l'espere, je la défendrai jusqu'à mon dernier soupir.22

Un sentimiento interior que trasciende todos los razonamientos, como escribe en los Fragments de la Lettre à $C$. de Beaumont: «Je n'ai sur ceci je l'avoüe que la preuve du sentiment, mais j'en suis fortement affecté». ${ }^{23} Y$ que enlaza con lo sobrenatural, como confiesa asimismo al escéptico $M$. Franquières: "L'homme à la fois raisonnable et modeste, dont l'entendement exercé mais borné, sent ses limites [...] saisi de respect, il s'arrête et ne touche point au voile, content de savoir que l'Etre immense est dessous". ${ }^{24}$

16 Ibídem: 1135

17 Ibídem: CXCl. Introducción a Lettres morales de H. Gouhier; Charles 2008: 278-284.

18 Rousseau 1969b: 60-61.

19 Como se aprecia, la biografía de Rousseau es una herramienta muy útil para explicar muchas de sus concepciones.

20 Rousseau 1969a: 1134.

21 Ibídem: 1070-1071.

22 Ibídem: 1075.

23 Ibídem: 1016.

24 Ibídem: 1137. 
Las creencias religiosas de Rousseau, como explica el propio autor en las Lettres écrites de la Montagne ${ }^{25}$, coinciden con las del vicario saboyano, que a su vez son muy similares a las de Julie, la protagonista de su novela La Nouvelle Héloïse. Ambos personajes son dos máscaras del propio Jean-Jacques, como señaló acertadamente Pierre Burgelin ${ }^{26}$, pero si Julie era una heroína imaginada e idealizada, el vicario existió realmente. Es sabido que Jean-Jacques conoció a un tal abbé Gaime o abbé Gâtier que le prestó ayuda en momentos difíciles de su juventud. En la "Profesión de fe del Vicario saboyano» se relatan dos historias paralelas, cuyos protagonistas representan ambos de un modo u otro a Rousseau. El vicario, inmerso en una profunda crisis, simboliza al Rousseau maduro, mientras que el calvinista fugitivo, obligado a cambiar de religión para sobrevivir, es el alter ego de Jean-Jacques en su juventud. ${ }^{27} \mathrm{El}$ personaje del fugitivo, que narra la historia de su adolescencia así como la del vicario, se quitará pronto la máscara y nos desvelará que su autobiografía es la del propio Rousseau. ${ }^{28}$

Podríamos datar el alejamiento definitivo de Rousseau de los «materialistas ateos» y el inicio de su cruzada a favor de la Providencia. La fecha sería el 18 de agosto de 1756, cuando da a conocer su llamada Lettre à Voltaire sur la Providence. En dicha carta, además de proclamar su creencia en Dios: «je crois en Dieu tout aussi fortement que je croye aucune autre vérité ${ }^{29}$, insiste en su incapacidad para permanecer en la duda. Frente a las desoladoras tesis de Voltaire, que ponen en cuestión la bondad de la Providencia, Rousseau apuesta por las doctrinas más optimistas y confortantes de Leibniz y Pope, que permiten soportar mejor las miserias de la existencia. ${ }^{30}$

Su respuesta al futuro Patriarca de Ferney se fundamenta sobre lo que más tarde será el tercer dogma de la «Profesión de fe del Vicario saboyano»: el hombre es libre y por lo tanto responsable de la mayor parte de los males que acontecen en el universo y que se achacan injustamente a Dios. Se trata de una concepción de libertad que se encuentra en sus dos Discursos, el de las Ciencias y el de la Desigualdad, una tesis muy alejada del determinismo spinozista (y del de Diderot), y que permite afirmar a Henri Gouhier que la antropología rousseauniana conduce a su teología. ${ }^{31}$

Su cruzada continúa un año más tarde, en noviembre de 1757, con las Lettres morales. Dirigidas a Sophie d'Houdetot (de quien estaba por entonces enamorado platónicamente), en dichas misivas le aconseja emprender una meditación seria para fijar, de una vez por todas, sus principios y

25 «On trouve dans l'Emile la profession de foi d'un Prêtre Catholique, et dans l'Héloïse celle d'une femme dévote. Ces deux Pieces s'accordent assez pourqu'on puisse expliquer l'une par l'autre [...] si l'Auteur qui a publié les Livres où elles sont contenues ne les adopte pas en entier l'une et l'autre, du moins il les favorise beaucoup». Rousseau 1964: 694.

26 Rousseau 1969a: CXXXIV. Introducción a Emile de P. Burgelin.

27 Como él, Rousseau se habría visto obligado a renunciar al protestantismo y convertirse al catolicismo en Turín, por necesidad de supervivencia.

28 Villaverde 2015: 211.

29 Rousseau 1969a: 1070

30 Ibídem: CLXXXVIII. Introducción a Lettre à Voltaire, Lettres morales, Notes sur 'De l'Esprit' y Lettre à M. Franquières de H. Gouhier.

31 Ibídem: CLXXXIX. le presenta un "código moral». ${ }^{32}$ La dama no se sintió particularmente interesada, al parecer, y Rousseau dejó de redactar sus lecciones. ${ }^{33}$ Sin embargo, algunas partes de dichas cartas (la quinta y la sexta) fueron posteriormente utilizadas por el ginebrino para componer el núcleo central de "La Profesión de fe del Vicario saboyano», integrado como sabemos en Emile, y que se publicó en 1762.

Entre tanto, entre 1756 y 1758, Rousseau trabajó en su novela La Nouvelle Heloïse. Pero en la primavera de 1758 , la lectura del libro de Helvétius De l'Esprit, virulento ataque contra el cristianismo, le impulsó a añadir dos apartados más a la novela para poner de manifiesto sus convicciones religiosas. $^{34}$

¿Qué conclusiones podemos extraer del análisis de todos estos escritos y qué aporta de nuevo El contrato social?

\section{DE LA TOLERANCIA Y LA LIBERTAD DE CONCIENCIA AL DOGMA- TISMO Y A LA INTRANSIGENCIA DE DU CONTRACT SOCIAL}

Las obras que acabo de examinar ponen de manifiesto el combate de un creyente -en este caso un calvinista asediado por las dudas - para abrirse paso entre las modernas y perturbadoras concepciones materialistas y ateas. Sin embargo en El contrato social la perspectiva cambia. Rousseau deja de pensar la religión como «útil e incluso necesaria» ${ }^{35}$ para mitigar la desazón individual, es decir circunscrita al ámbito privado, para convertirla en un instrumento social que incita a los ciudadanos "a amar sus deberes ". ${ }^{36}$ A diferencia de los ilustrados como D'Holbach o Diderot, que prescindieron de la religión como moral para el pueblo y la confinaron a la esfera privada, el ginebrino necesitaba apelar al sistema de castigos y recompensas del más allá para apuntalar el orden socio-político de su comunidad ideal. ${ }^{37}$

Así en Du contract social, después de diseñar una sociedad ejemplar que garantiza la libertad e igualdad de todos sus miembros (a diferencia de la propuesta por sus predecesores Hobbes y Locke) ${ }^{38}$, incluye, como colofón al final del libro, un capítulo sobre la religión, donde ésta juega el papel de cemento que da consistencia a todo el edificio socio-político que acaba de construir. Una religión que se configura como sostén moral, como instrumento coactivo para asegurarse la obediencia de los súbditos. De ahí las diferencias de Rousseau con sus contemporáneos ilustrados

\footnotetext{
32 Ibídem: CXC.

33 Ibídem: CXCII.

34 Escribió también una decena de páginas en «Notes sur 'De
} l'Esprit'», que están publicadas en las Oeuvres complètes IV (1121-1130). Y en una nota de las Lettres écrites de la montagne (Oeuvres complètes III: 693), sin citar el libro ni el autor, afirma que, desde su publicación en 1758 , había decidido atacar sus principios.

35 Rousseau 1964: 695.

36 Ibídem: L. IV, cap. VIII: 468.

37 A pesar de su aparente optimismo antropológico y de su también aparente confianza en la razón, Rousseau no tiene, en el fondo, suficiente confianza en la bondad natural del ser humano ni en su capacidad para guiarse por su razón por lo que tiene que invocar a lo religioso.

38 En efecto, el objetivo de El contrato social consiste en «encontrar una forma de asociación que defienda y proteja de toda fuerza común a la persona y a los bienes de cada asociado, y gracias a la cual cada uno, en unión de todos los demás, solamente se obedezca a sí mismo y quede tan libre como antes». Rousseau 1988: 14. 
y las semejanzas con el Maquiavelo de los Discorsi: «Los que estén a la cabeza de una república o un reino - afirma el florentino- deben, pues, mantener las bases de su religión, y hecho esto, les será fácil mantener al país religioso, y por tanto bueno y unido». ${ }^{39}$

Maquiavelo, maestro del realismo, había advertido reiteradamente de la necesidad que tienen todos los legisladores ${ }^{40}$ de «recurrir a lo sobrenatural». ${ }^{41} Y$ no había tenido escrúpulos en alabar cualquier superstición o religión falsa que cumpliera la función de fortalecer la República: "éste ha sido el proceder de los sabios, y de aquí nació la autoridad de los milagros que se celebran en las religiones, aunque sean falsos». ${ }^{42}$

Así dedica el capítulo 11 del libro primero de los Discorsi a ensalzar la religión romana establecida por Numa, quien "encontrando un pueblo ferocísimo, y queriendo reducirlo a la obediencia civil con artes pacíficas, recurrió a la religión como elemento imprescindible para mantener la vida civil». ${ }^{43}$ Para ello Numa simuló «tener familiaridad con una ninfa que le aconsejaba todo lo que luego él aconsejaba al pueblo» y lo hacía porque "temía que su autoridad sola no bastase ${ }^{44}$

Ciertamente Rousseau, creyente sincero, carecía del cinismo del incrédulo secretario florentino quien exaltaba las supersticiones romanas con tal de asegurarse el respeto a las leyes. Aun así, como veremos a continuación, muchas de las inquietantes propuestas que se encuentran en el capítulo sobre la religión de El contrato social y en algunos de sus otros escritos recuerdan a Maquiavelo.

\section{Una religión de la tolerancia}

Las concepciones religiosas de Rousseau suelen enmarcarse en el contexto del pensamiento religioso ilustrado ${ }^{45}$, que reivindica la capacidad de la razón para acceder a las verdades religiosas. Así parece desprenderse, por ejemplo, de su Lettre à D'Alembert donde declara: "Je suis l'ami de toute religión paisible, où l'on sert l'Etre éternel selon la raison qu'il nous a donnée». ${ }^{46}$

Esta reivindicación de la razón era compartida en la época tanto por los deístas como por las sectas radicales, desde el socinianismo a otros sectores liberales del calvinismo. De ahí la supuesta cercanía de Rousseau al ala «liberal» protestante, acusada de socinianismo e influenciada por algunas tesis spinozistas, en particular por la crítica bíblica del Tratado Teológico-Político y la apología de la tolerancia religiosa. ${ }^{47} \mathrm{Y}$, aunque Jean-Jacques siempre negó ser un sociniano ${ }^{48}$, si leemos las Lettres écrites de la Montagne

39 Maquiavelo 2003: 72.

40 El énfasis es mío: «Nunca hubo un legislador que diese leyes extraordinarias a un pueblo y no recurriese a Dios, porque de otro modo no serían aceptadas». Ídem.

41 Ibídem: 69, nota 27.

42 Ídem.

43 Ibídem: 67.

44 Ibídem: 69

45 Ver, por ejemplo, la obra clásica de Cassirer 1975.

46 Rousseau 1967b: 58.

47 Vernière 1954: 37.

48 Rousseau, sin embargo, se muestra reacio a admitir su afinidad con una doctrina condenada como herética, a pesar del testimonio de algunos de sus contemporáneos como el abate Bergier. Abbé Bergier constataremos hasta qué punto su calvinismo escoraba hacia el socinianismo. ${ }^{49}$ En efecto, la religión tolerante, natural, dulce y pacífica a la que alude en la Lettre à D'Alembert ${ }^{50}$ de 1758 , así como en la Note responsive à $M$. de Malesherbes ${ }^{51}$ de 1761, (donde reconoce haber puesto en boca de SaintPreux, el personaje de La Nueva Eloísa, las tesis socinianas) es el socinianismo ${ }^{52}$, una religión sin dogmas que proclama la libertad de conciencia y predica la tolerancia hacia todos los credos religiosos. ${ }^{53}$

Y ciertamente encontramos en sus obras una exaltación de ambos valores. Por ejemplo, en la conocida como Lettre à Voltaire sur la Providence, se muestra como un abanderado de la libertad religiosa: "Mais je suis indigné, comme vous, que la foi de chacun ne soit pas dans la plus parfaite liberté, et que l'homme ose controller l'intérieur des consciences». ${ }^{54}$ Libertad de conciencia que reivindica también en los Fragments de la Lettre à Christophe de Beaumont ${ }^{55}$, así como en las Lettres écrites de la Montagne ${ }^{56}$, donde sostiene que, por muy obtuso que sea el entendimiento de una persona, nadie está obligado a someterse a la razón de otro ${ }^{57}$, ni a aceptar las opiniones ajenas como regla de fe o norma de conducta: "Il est tellement de l'essence de la raison d'être libre, que quand elle voudroit s'asservir à l'autorité, cela ne dépendroit pas d'elle». ${ }^{58}$ Tesis que ratifica en Emile: "La foi s'assure et s'affermit par l'entendement [...] le Dieu que j'adore [...] ne m'a point doüé d'un entendement pour m'en interdire l'usage; me dire de soumettre ma raison c'est outrager son auteur». ${ }^{59}$

En cuanto a la defensa de la tolerancia, se pueden encontrar asimismo párrafos de gran contundencia en todos sus escritos. Por ejemplo, en Emile afirma con rotundidad que "toutes les Réligions sont bonnes et agréables à Dieu»" y exhorta a la tolerancia: «à-Dieu-ne-plaise que jamais je leur prêche le dogme crüel de l'intolérance, que jamais je les porte à détester leur prochain, à dire à d'autres hommes: vous seres dannés" ${ }^{61} Y$ en la carta a Christophe de Beaumont, muestra asimismo su faceta más tolerante:

1771: II, 103-104. En la Lettre à d'Alembert escribe: «Je ne sais ce que c'est le socinianisme, ainsi je n'en puis parler ni en bien ni en mal et même sur quelques notions confuses de cette secte et de son fondateur, je me sens plus d'éloignement que de goût pour elle». Rousseau 1967b: 58.

49 El abate Bergier también cataloga a Rousseau de sociniano, ampliando el marco de influencia de esta doctrina a todos los protestantes suizos, lo que probablemente era una exageración.

50 Rousseau 1967b: 11 y 58.

51 Rousseau 1974: 57 y ss.

52 Jedryka 1973: 29. Para una bibliografía más actualizada ver AA. VV. 2005. Fausto Sozzini e la filosofia in Europa. [Atti del Convegno Siena 25-27, Novembre 2004, Siena].

53 Villaverde 2010-2011: 347-348.

54 Rousseau 1969a: 1072.

55 Ibídem: 1024.

56 Rousseau 1964: 699.

57 Éste es un principio que Rousseau comparte con los teóricos del Derecho natural y que Pufendorf formula así: «Mais il feroit très-abfurde de s'imaginer, que la Nature elle-même donne d'abord actuellement aux plus éclairez \& aux plus fages la conduite des autres, ou du Moinz le droit de les obliger, malgré eux, à obéir». Pufendorf 1732: L. III, cap. II, párrafo VIII, 316-317.

58 Rousseau 1964: 713-714.

59 Rousseau 1969a: 614.

60 Ibídem: 609. Ver también: «Je regarde toutes les réligions particulieres comme autant d'institutions salutaires». Ibídem: 627.

61 Ibídem: 628. 
A l'egard des objections sur les sectes particulieres [...] que ne puis-je [...] porter chaque homme à l'indulgence, à la douceur, par cette considération si frappante et si naturelle; que s'il fût né dans un autre pays, dans une autre secte, il prendroit infailliblement pour l'erreur ce qu'il prend pour la vérité, et pour la vérité ce qu'il prend pour l'erreur. ${ }^{62}$

Una faceta que va acompañada de una dura condena de la intolerancia: "les doctrines abominables sont celles qui mènent au crime, au meurtre, et qui font des fanatiques». ${ }^{63}$ Porque la intolerancia y el fanatismo - afirma - enfrentan a los hombres y los convierten en enemigos ${ }^{64}$ : «La superstition - escribe en las Lettres écrites de la Montagne ${ }^{65}$ - est le plus terrible fléau du genre humain; elle abbrutit les simples, elle persécute les sages, elle enchaîne les Nations, elle fait par tout cent maux effroyables».

También algunos párrafos de La Nouvelle Héloïse revelan un rechazo contundente de la intolerancia: «Nul vrai croyant ne sauroit être intolérant ni persécuteur. Si j'étois Magistrat, \& que la loi portât peine de mort contre les athées, je commencerois par faire brûler comme tel quiconque viendroit dénoncer un autre». ${ }^{66}$

Tal vez sea en esta novela donde la tolerancia de Rousseau llega más lejos porque alcanza incluso a los ateos, en línea con Pierre Bayle o Voltaire, quienes conjeturaban sobre la existencia de ateos virtuosos. Rousseau nos describe, en efecto, al marido de Julie, el ateo Wolmar, con todos los rasgos de un honnête homme: "si sage, si raisonnable, si loin de toute espèce de vice, si peu soumis aux passions humaines ${ }^{67}$ Pero una lectura más atenta de la novela revela algunas fisuras. Ese ateo virtuoso lleva, sin embargo, en el fondo de su corazón "l'affreuse paix des méchans» ${ }^{68}$, una paz conquistada a costa de la "alienación del ser ${ }^{69}$, de la negación de las verdades religiosas y morales en aras de la hegemonía de la razón, que le provoca remordimiento y angustia. ${ }^{70} \mathrm{~A}$ pesar de estar dotado de todo tipo de cualidades, Wolmar carece de algo tan esencial como la "prueba interior o del sentimiento».

Parece como si a Jean-Jacques le costase en el fondo admitir que un ateo pueda ser un hombre de bien. De ahí que, en la novela, Wolmar mantenga en secreto su ateísmo para no arrebatar "consuelo y alivio a los que sufren", y para no ejercer una mala influencia sobre sus hijos. Se presta incluso a acudir a la iglesia con su familia y a someterse a las costumbres establecidas. ${ }^{71}$ Rousseau valora que, sin hacer alarde de una fe de la que carece, evite el

\footnotetext{
62 Ibídem: 983-984.

63 Ibídem: 985.

64 Ibídem: 628.

65 Rousseau 1964: 695.

66 Rousseau 1961: 589.

67 Ibídem: 588.

68 ídem.

69 Rousseau 1961. Introducción a La Nouvelle Héloïse de B. Guyon.

70 «En voulant s'éclaircir de bonne foi sur ses matieres, il s'étoit enfoncé dans les ténebres de la métaphysique où l'hommme n'a d'autres guides que les systèmes qu'il y porte, \& ne voyant par-tout que doutes et contradictions, quand enfin il est venu parmi des Chrétiens il y est venu trop tard, la foi s'étoit déja fermée à la vérité, sa raison n'étoit plus accessible à la certitude ( ) il a fini par combattre également les dogmes de toute espece, \& n'a cessé d'être athée que pour devenir sceptique». Rousseau 1961: 589.
}

71 Ibídem: 592. escándalo y cumpla como buen ciudadano con el culto que establecen las leyes. ${ }^{72}$ Así pues el ateo Wolmar no cree pero se comporta como si creyera. ¿No es esto en el fondo una muestra de intolerancia?

La idea de una sociedad de ateos virtuosa, que había insinuado Pierre Bayle y de alguna manera también Voltaire, refiriéndose a Spinoza, no dejaba de ser problemática en la época. La sociedad no estaba aun suficientemente madura para confiar en quienes no temían a Dios, en quienes carecían de obstáculos morales a la hora de comportarse. ${ }^{73}$ Rousseau seguía pensando, en la tradición de Maquiavelo y de numerosos autores de los siglos XVII y XVIII, que sin religión no se podía ser un buen ciudadano.

\section{Los dogmas de la profesión de fe de Rousseau}

Peu de gens ont une idée juste de la religion. On la fait ordinairement consister dans des pratiques extérieures, et l'on ne remplit aucun des devoirs essentiels qu'elle prescrit. Il faut sans doute observer les préceptes de l'Eglise, mais ne pas s'imaginer qu'en assistant au service divin, et en marmotant quelques prières où le coeur n'est pour rien, on a tout fait.// On n'a de religion qu'autant qu'on ne fait pas contre les autres ce que nous ne voudrions pas qu'ils fissent contre nous, et qu'on fait pour eux ce que nous voudrions qu'ils fissent pour nous.// La véritable religion, c'est la vérité, la charité, la bienfaisance, l'humilité, la douceur dans le caractère et dans les procédés. Tout exercice de religión qui n'est pas fondé sur cette base, n'est qu'illusion et hyprocrisie. $^{74}$

Este largo párrafo de una de las obras menos conocidas de Rousseau, Pensées d'un esprit droit et sentimens d'un coeur vertueux, expone claramente cuál es su alternativa religiosa. Se trata de una religión natural basada en las buenas obras: «non seulement il faut être homme de bien, miséricordieux, humain, charitable, mais que quiconque est vraiment tel en croit assez pour être sauvé» ${ }^{75}$ y desprovista de ceremonial y de ritos: «Ni rites superstitieux, ni subtilités dans la doctrine, elle ira toute entiere à son vrai but, qui est la pratique de nos devoirs». ${ }^{76}$ Una religión aparentemente democrática y tolerante que solo requiere admitir "les principes des devoirs de l'homme et du Citoyen; du reste, croyez tout ce qu'il vous plaira». ${ }^{77}$

Al sostener que la validez de una doctrina no depende de sus dogmas, sino de su moral, Rousseau parece coincidir con Spinoza. ${ }^{78}$ Este, en efecto, resumía en el Tratado Teológico-Político la esencia de las Escrituras en la necesidad de "obedecer a Dios con un corazón puro», máxima que Rousseau retoma y convierte en «le culte que Dieu demande est celui du cœur». ${ }^{79} \mathrm{Y}$ si para Spinoza la religión consiste en

72 Ibídem: 592-593.

73 Es cierto que la condena de los ateos era usual en el siglo XVIII, incluso entre autores tolerantes como Locke o Pierre Bayle. El argumento para excluirles era que los ateos no eran capaces de mantener los acuerdos y juramentos sobre los que se basa la sociedad; pero además aquellos que no tienen religión no pueden reclamar el privilegio de la tolerancia. Hunter 2011: 138-139.

74 Rousseau 1961: 1301

75 Rousseau 1969a: 962.

76 Rousseau 1964: 701.

77 Ídem.

78 Villaverde 1999: 117-139.

79 Rousseau 1969a: 608. 
"la justicia y la caridad o en el amor al prójimo ${ }^{80}$, Rousseau lo traduce como "servir Dieu, aimer son prochain, obéir aux Loix». ${ }^{81}$ La práctica es para ambos autores el eje de la doctrina, la columna vertebral de la religión:

Jesus-Christ [...] a peu subtilisé sur le dogme, et beaucoup insisté sur les devoirs; il prescrivoit moins d'articles de foi que de bonnes oeuvres; il n'ordonnoit de croire que ce qui étoit nécessaire pour être bon [...] celui qui aime son frere a accompli la Loi. ${ }^{82}$

Por el contrario, las cuestiones especulativas quedan aparcadas y el culto exterior, relegado: «quant au culte extérieur, s'il doit être uniforme pour le bon ordre, c'est purement une affaire de pólice». ${ }^{83}$ Que cada uno crea lo que quiera, insiste Rousseau en la Lettre à D'Alembert ${ }^{84}$, lo importante es que cumpla con sus deberes sociales y sea tolerante con los demás. «Voila la véritable religion, voila la seule qui n'est susceptible ni d'abus ni d'impieté ni de fanatisme», repite en Emile. ${ }^{85} \mathrm{Y}$ en la carta al arzobispo de París, reitera:

Quant aux opinions qui ne tiennent point à la morale, qui n'influent en aucune maniere sur les actions, et qui ne tendent point à transgresser les Loix, chacun n'a là-dessus que son jugement pour maître, et nul n'a ni droit ni intérêt de prescrire à d'autres sa façon de penser. ${ }^{86}$

Es cierto que estos escritos inducen a pensar que la esfera de las creencias religiosas queda excluida del control del Estado y que éste no se inmiscuye en el ámbito de la conciencia individual, donde nadie tiene derecho a entrar. ${ }^{87}$ Tesis que reitera en Du Contract social, donde Rousseau insiste en que al Estado solo le competen los dogmas en cuanto atañen a la moral y a los deberes de los ciudadanos: «Les sujets ne doivent donc compte au Souverain de leurs opinions qu'autant que ces opinions importent à la communauté». ${ }^{88}$ Sus restantes concepciones religiosas -insiste posteriormente en las Lettres écrites de la Montagne- no son de la incumbencia del Estado que no tiene competencia sobre el más allá ni sobre el destino ultraterreno de sus súbditos. ${ }^{89}$

Sin embargo esta argumentación se resquebraja en buena medida cuando el ginebrino establece que hay opiniones personales que sí importan a la comunidad:

Pourquoi un homme a-t-il inspection sur la croyance d'un autre, et pourquoi l'Etat a-t-il inspection sur celle des Citoyens? C'est parce qu'on suppose que la croyance des hommes détermine leur morale, et que des idées qu'ils ont de la vie à venir dépend leur conduite en celle-ci. ${ }^{90}$

\footnotetext{
80 Spinoza 1986: 314.

81 Rousseau 1964: 802.

82 Rousseau 1969a: 960.

83 Ibídem: 608.
}

84 «Monsieur, jugeons les actions des hommes, et laissons Dieu jugar de leur foi». Rousseau 1967b: 62.

85 Rousseau 1969a: 729.

86 Ibídem: 973.

87 Ídem.

88 Rousseau 1964: 467-468.

89 «Les Magistrats, les rois n'ont aucune autorité sur les ames, et pourvu qqu'on soit fidelle aux Loix de la société dans ce monde, ce n'est point à eux de se mêler de ce qu'on deviendra dans l'autre, où ils n'ont aucune inspection». Rousseau 1964: 711.

90 Rousseau 1969a: 973.
Pero ¿qué opiniones importan a la comunidad? «Il importe bien à l'Etat que chaque Citoyen ait une Religion qui lui fasse aimer ses devoirs». ${ }^{91}$ De momento la libertad religiosa parece quedar a salvo pues el único requisito exigido es que los ciudadanos tengan una religión que les impulse a amar sus deberes. $Y$ todas las religiones predican valores morales semejantes: justicia, amor al prójimo, etcétera. Rousseau ni siquiera se distanciaría de Spinoza ${ }^{92}$, el más tolerante de los autores de los siglos XVII y XVIII ${ }^{93}$, que valora la utilidad de la religión para los incapaces de regirse por su razón y, por lo tanto, necesitados de reglas morales y de pastores que los conduzcan.

Pero si para Spinoza cualquier religión puede cumplir esa función ${ }^{94}$, incluido el Islam, lo que muestra el alcance de su tolerancia, para Rousseau, en realidad, no todas las religiones son válidas. A partir del supuesto de que las creencias religiosas de los hombres determinan su moral, y de que su conducta en esta vida depende de las concepciones que tengan sobre la vida ultraterrena, el ginebrino otorga al Estado derecho de inspección sobre éstas. Así, en la Lettre à Christophe de Beaumont, escribe: "dans la société chacun est en droit de s'informer si un autre se croit obligé d'être juste, et le Souverain est en droit d'examiner les raisons sur lesquelles chacun fonde cette obligation $"{ }^{95} \mathrm{Y}$ en Du contract social ya había declarado la competencia del Estado para fijar dogmas religiosos:

Il y a donc une profession de foi purement civile dont il appartient au Souverain de fixer les articles, non pas précisement comme dogmes de Religion, mais comme sentimens de sociabilité, sans lesquels il est impossible d'être bon Citoyen ni sujet fidelle. ${ }^{96}$

Su tolerancia se limita así a aquellos aspectos de la religión que considera indiferentes, como los dogmas especulativos, el ritual y el ceremonial, pero no incluye, a pesar de sus afirmaciones, las creencias que juzga esenciales. ${ }^{97}$ Estas son, como expone en Du contract social, la existencia de un Dios cuyas cualidades enuncia de manera pormenorizada: poderoso, inteligente, bienhechor, previsor y providente, y la creencia en la vida ultraterrena, con el premio a los justos y el castigo a los malvados:

Les dogmes de la Religion civile doivent être [...] l'existence de la Divinité puissante, intelligente,

\footnotetext{
91 Rousseau 1964: 468.

92 «Hay que dejar a todo el mundo la libertad de opinión y la potestad de interpretar los fundamentos de la fe según su juicio ( ) esa misma libertad puede y debe ser concedida sin menoscabo de la paz del Estado ( ) y no puede ser abolida sin gran peligro para la paz y sin gran detrimento para todo el Estado». Spinoza 1986: 70-71.

93 Villaverde 2012: 31.

94 «Los dogmas de la fe universal ( ) que existe un ser supremo, que ama la justicia y la caridad, al que deben obedecer todos para salvarse, $y$ al que deben adorar mediante la práctica de la justicia y la caridad hacia el prójimo». Spinoza 1986: 314.

95 Rousseau 1969a: 973.

96 Rousseau 1964: 468.

97 Como escribe Bergier: «según sus principios, todas las opiniones particulares en materia de religión interesan a la comunidad. Le interesa mucho saber si un sujeto profesa la religión nacional, o si se limita a creer en la religión del hombre; porque la primera ata fuertemente el corazón de los ciudadanos al Estado, mientras que la segunda les separa y les otorga un espíritu contrario al espíritu social». Abbé Bergier 1771: II, 91-92. La traducción es mía.
} 
bienfaisante, prévoyante et pourvoyante, la vie à venir, le bonheur des justes, le châtiment des méchans, la sainteté du Contract social et des loix; voilà les dogmes positifs. Quant aux dogmes négatifs, je les borne à un seul; c'est l'intolérance: elle rentre dans les cultes que nous avons excluds. ${ }^{98}$

Dogmas que enuncia asimismo en la primera parte de la "Profesión de fe del Vicario saboyano ${ }^{99}$ y que se resumen en la creencia en un primer motor que mueve el universo ${ }^{100}$; en una voluntad a la que llamamos Dios ${ }^{101}$; y en la inmortalidad del alma. ${ }^{102}$ A los que habría que añadir la creencia en la libertad del hombre (que le diferencia radicalmente de los animales).

Más tarde, en las Lettres écrites de la Montagne, publicadas en noviembre de 1764, desarrollará sus postulados religiosos. ${ }^{103} \mathrm{Y}$ dividirá la religión en dos partes (dejando de lado el ceremonial): los dogmas y la moral; subdivide, a su vez, los dogmas en los que sirven de fundamento a la moral y establecen deberes, y los que tienen un carácter especulativo. ${ }^{104}$ En cuanto a los primeros, que se refieren a la justicia, el bien público, la obediencia a las leyes (naturales y positivas), las virtudes sociales y todos los deberes del hombre y del ciudadano, Rousseau deja bien claro que son competencia del gobierno y ámbito de su jurisdicción. ${ }^{105}$

Si releemos ahora los escritos de Rousseau a partir de estos supuestos, se producirá un vuelco en nuestra valoración de su tolerancia. En efecto, sus dogmas podrían ser aceptados por los teístas pero un buen número de deístas quedaría excluido. Además, Rousseau deja fuera a las religiones «incompatibles con los deberes del ciudadano», léase la religión católica en particular, que queda prohibida y sus fieles expulsados de la ciudad ideal diseñada en Du contract social, en tanto que "enemigos del género humano».

$Y$ es que Rousseau, como Maquiavelo ${ }^{106}$, critica las religiones que predican la sumisión y no impulsan el espíritu cívico: «La patrie du Chrétien n'est pas de ce monde» declara en Du contract social. ${ }^{107} \mathrm{Y}$ alaba las religiones cívicas como la romana que, a través de ritos y supersticiones, promovieron el patriotismo. ${ }^{108}$

En línea con el secretario florentino, Rousseau ensalza en las Considérations sur le Gouvernement de Pologne, a tres legisladores de la Antigüedad, Moisés, Licurgo y Numa, que fueron capaces de dotar a sus pueblos de lo que hoy llamaríamos una identidad nacional mediante hábitos, ritos y ceremonias exclusivos, que forjaron lazos de fraternidad entre los ciudadanos y alzaron barreras que les separaron de sus vecinos. ${ }^{109}$

\footnotetext{
98 Rousseau 1964: 468-469.

99 Es cierto, sin embargo, que dichos dogmas no están exentos de dudas. Ver, por ejemplo, Rousseau 1969a: 581, 591, 593 y 603 e ibídem:

100 Ibídem: 576

101 «Cet être, enfin, quel qu'il soit, qui meut l'univers et ordonne toutes choses, je l'apelle Dieu». Ibídem: 581. Ver también 578.

102 Ibídem: 587.

103 Rousseau 1964. Introducción de Jean-Daniel Candaux: CLXXV.

104 Ibídem: 694.

105 Ibídem: 694-695.

106 Villaverde 2001: 14.

107 Rousseau 1964: 466

108 Rousseau, como Maquiavelo alaba a Numa. Ibídem: 957.

109 Ibídem: 957.
} 995.
Pero la religión católica no solo es condenada por su carencia de espíritu cívico sino por su intolerancia: «on doit tolérer toutes celles qui tolerent les autres [...] Mais quiconque ose dire, hors de l'Eglise point de Salut, doit être chassé de l'Etat». ${ }^{110}$ La referencia al catolicismo, una religión que considera "tiránica» ${ }^{111}$ y supersticiosa, basada en dogmas incomprensibles y en oscuras profecías, es clara. El rechazo de Rousseau a la religión católica es casi visceral. En Du contract social la describe como «si evidemment mauvaise que c'est perdre le tems de s'amuser à le démontrer». ${ }^{112} \mathrm{Y}$ en la Lettre à Christophe de Beaumont opta por marginar a los católicos del tratado de paz en el que participarían los judíos, las restantes sectas cristianas y los turcos. ${ }^{113}$

Es cierto que las invectivas contra los "papistas» eran frecuentes en los círculos ilustrados franceses, dada la mala reputación de la Iglesia católica. Pensemos, por ejemplo, en Voltaire y su cruzada contra el Infâme. Y lo mismo ocurría en los países protestantes desde el siglo XVII, como lo prueba el ataque de Hobbes al Papado en el último capítulo del Leviatán, donde lo describe como un reino de tinieblas. ${ }^{114}$

Destacando los aspectos más democráticos de la Reforma, el ginebrino traza una línea de demarcación entre la religión católica, fundamentada sobre la sumisión, y el protestantismo que se yergue sobre la razón ${ }^{115}$, la libertad de conciencia y la tolerancia: "La Religion Protestante est tolérante par principe [...] puisque le seul dogme qu'elle ne tolere pas est celui de l'intolérace». ${ }^{116}$ Pero su afinidad con los principios de la Reforma no le impide condenar el luteranismo, tan intolerante como la Iglesia romana ${ }^{117}$, censurar la «dura» ortodoxia de Calvino, a quien sin embargo respeta ("Calvin, sans doute, étoit un grand homme»)118, y criticar a los Reformadores por haber traicionado el espíritu de la Reforma y haberse convertido, de perseguidos, en perseguidores. ${ }^{119} \mathrm{Su}$ aversión hacia la intolerancia llega hasta el punto de preferir prescindir de religión a profesar una «intolerante y asocial» como el catolicismo ${ }^{120}$, que provoca disensiones, disturbios y todo tipo de guerras, e incita a los hombres a degollarse los unos a los otros. ${ }^{121}$ De ahí su virulenta arremetida Du contract social: «je ne connois rien de plus contraire à l'esprit social». ${ }^{122}$

Pero a la intransigencia hacia los católicos se suma la intolerancia hacia los ateos, a quienes excluye del pacto de tolerancia que propone en la carta al arzobispo de París. Mientras que judíos, musulmanes y algunos grupos cristianos participarían, los idólatras y los ateos quedan apartados. Jean-Jacques podría en último extremo tolerar a los paganos ${ }^{123}$, pero nunca a los «materialistas y ateos» a

\footnotetext{
110 Ibídem: 469.

111 Ibídem: 702

112 Ibídem: 464.

113 Rousseau 1969a: 974.

114 Hobbes 1983: 729.

115 Rousseau 1969b: 82

116 Rousseau 1964: 716.

117 Ibídem: 716, nota.

118 Ibídem: 715.

119 Ídem.

120 Ibídem: 705.

121 Rousseau 1969a: 974.

122 Rousseau 1964: 465.

123 Rousseau 1969a: 556.
} 
los que considera perturbadores del orden y enemigos de la sociedad. Esta intransigencia hacia los ateos, levemente esbozada en La Nouvelle Héloïse, es manifiesta tanto en Du contract social como en la Lettre à Christophe de Beaumont, donde condena al destierro a quienes no acepten su "catecismo del ciudadano»:

Formez de ce petit nombre d'articles une Religion universelle, qui soit, pour ainsi dire, la Religion humaine et sociale, que tout homme vivant en société soit obligé d'admettre. Si quelqu'un dogmatise contre elle, qu'il soit banni de la société, comme ennemi de ses Loix fondamentales. ${ }^{124}$

En ambos escritos, Rousseau exige el respeto a los dogmas básicos de su credo (que consisten esencialmente, como hemos visto, en la creencia en Dios y en la vida ultraterrena) bajo pena de destierro. ${ }^{125}$ Pero en Du contract social va más allá y sentencia a la pena de muerte a quienes finjan admitirlos y no los acaten: "Que si quelqu'un, après avoir reconnu publiquement ces mêmes dogmes, se conduit comme ne les croyant pas, qu'il soit puni de mort». ${ }^{126}$

Sentencia drástica e insólita en boca de un pretendido apóstol de la tolerancia. Insólita porque ninguno de los autores supuestamente tolerantes de los siglos XVII y XVIII Ilega tan lejos en las medidas contra los ateos. ${ }^{127} \mathrm{Y}$ sorprendente porque dista mucho de la tolerancia que tanto predica. Y es que el marco de tolerancia que Rousseau está dispuesto a aceptar tiene límites precisos y uno de ellos es la creencia en Dios.

A la exclusión de ateos y católicos, se añade su intolerancia hacia las mujeres, que ya denunció su contemporáneo, el abate Bergier ${ }^{128}$ :

Ah, señor, iqué digno de lástima es este sexo! No son la <evidencia y la razón> las que regulan su fe sino que sus creencias <están sometidas a la autoridad> [...] Todos los artículos de su religión son para ellas misterios y, en consecuencia, cosas absurdas que están obligadas a creer bajo palabra de sus maridos [...] Pero, podrían responder, puesto que saben responder: no somos animales ni autómatas sino que hemos recibido de Dios al igual que los hombres un juicio; <necesitamos razones para someter nuestra razón $>$ y no se nos dan y ni siquiera se toman la molestia de <explicarnos las razones que existen para creer $>.{ }^{129}$

Entrecomillando palabras del propio Rousseau, el abate le reprocha no conceder a las mujeres la libertad religiosa, columna vertebral de la Reforma que exige para los varones, e imponerlas el "yugo de la fe» y una "obediencia ciega». ${ }^{130}$ $Y$, en efecto, mientras los varones deben guiarse, según Rousseau, por su razón y gozar de una plena libertad de creencias, "l'autorité doit régler la religion des femmes». El

\section{Ibídem: 976.}

125 «Sans pouvoir obliger personne à les croire, il peut bannir de l'Etat quiconque ne les croit pas». Rousseau 1964: 468.

126 Ídem.

127 Ni Locke ni, por ejemplo, Voltaire que admira al Senado romano, al que califica de reunión de ateos.

128 Resulta sorprendente que quien denuncia las posiciones misóginas de Rousseau sea un católico tachado de intransigente por los philosophes.

129 Abbé Bergier 1771: II, 55-56.

130 Ibídem: II, 56. argumento que alega es que son incapaces de «tirer d'elles seules la régle de leur foi [...] par cela même que la conduite de la femme est asservie à l'opinion publique, sa croyance est asservie á l'autorité». ${ }^{131}$ De ahí su conclusión de que «toute fille doit avoir la religion de sa mére et toute femme celle de son mari». ${ }^{132}$

Ahora bien, si Rousseau no concede la libertad de conciencia a las mujeres, si expulsa a los católicos de su comunidad del Contract social, y si impone a los ateos su catecismo del ciudadano ¿dónde reside su tolerancia? ¿Deberíamos concluir que es falsa, o peor aún, que el ginebrino es un apóstol del despotismo, como le califica Bergier?

Apóstol del despotismo porque su catecismo de $D u$ Contract social incluye tanto dogmas civiles (la creencia en la santidad del contrato social y de las leyes) como religiosos (la creencia en Dios y en la vida ultraterrena) y concede jurisdicción al soberano para establecer los preceptos religiosos. Frente a esa "peligrosa confusión» de lo sagrado y lo profano, el abate elogia la separación de las dos legislaciones, la política y la eclesiástica, propia de los países católicos que, según la doctrina de Montesquieu, impide el abuso de poder. ${ }^{133}$

Según la crítica de Bergier, el despotismo religioso iría acompañado de un "patriotismo fanático» inspirado en los héroes griegos y romanos, que concibe la patria como «un ídolo al que hay que inmolar el mundo entero" y al ciudadano como "un republicano feroz», preocupado únicamente por la ciudad donde ha nacido y cuyo único afán es convertirla en dueña del universo al precio que sea. ${ }^{134}$ "Aunque la sociedad careciera de tales héroes, ¿habría perdido algo?» - se pregunta el abate- - "Habría habido menos usurpaciones y crímenes, menos sangre vertida, menos provincias arrasadas, menos ciudades reducidas a cenizas $» .{ }^{135}$

Aunque Rousseau alaba en ocasiones el humanitarismo cristiano que introdujo el derecho de gentes, suavizó las costumbres y humanizó a los gobiernos ${ }^{136}$, pronto abandonó dicho humanitarismo porque, como denuncia Bergier, lo considera «en el fondo más nocivo que útil para la constitución del Estado». ${ }^{137} Y$ es que, a juicio del ginebrino, las filosofías y las religiones humanitarias crean hombres justos y amigos de la paz, y por ello son beneficiosas para el género humano, pero aflojan los vínculos políticos ${ }^{138}$ y debilitan el patriotismo ${ }^{139} \mathrm{y}$, por ende, son perjudiciales para el Estado. Como confiesa en las Lettres écrites de la

\footnotetext{
131 Rousseau 1969a: 721. Las tres citas en la misma página.

132 Ídem.

133 Villaverde 2011: 257-258.

134 Abbé Bergier 1771: II, 132. La traducción de las citas del abate Bergier es mía.

135 Ibídem: II, 157.

136 Prueba de ello es su Segundo Discurso donde, bajo la influencia de Diderot, el ginebrino elogia a las «grandes Ames Cosmopolites qui franchissent les barriéres imaginaires qui séparent les Peuples». Rousseau 1964: 178.

137 Abbé Bergier 1771: II, 156.

138 Rousseau denuncia que, en su época, todas las naciones son iguales en mezquindad, en mediocridad, y que su horizonte está marcado solamente por intereses económicos. He ahí a donde conduce, a su juicio, el abandono del patriotismo. «Il n'y a plus aujourd'hui de François, d'Allemands, d'Espagnols, d'Anglois mème ( ) il n'y a que des Européens». Rousseau 1964: 960.

139 Ibídem: 536.
} 
Montagne, el patriotismo y el humanitarismo son dos virtudes incompatibles ${ }^{140}$ :

Loin de taxer le pur Evangile d'être pernicieux à la société, je le trouve, en quelque sorte, trop sociable, embrassant trop tout le genre humain [...] inspirant I'humanité plutôt que le patriotismme, et tendant à former des hommes plutôt que des Citoyens. ${ }^{141}$

Así, mientras el abate Bergier, católico intransigente, ensalza el humanitarismo cristiano por haber suprimido la esclavitud y anudado vínculos entre los seres humanos ${ }^{142}$, Rousseau, a pesar de algunas vacilaciones, acaba condenándolo por alentar la fraternidad universal y oponerse al patriotismo. Parecería incluso que, puestos a elegir, se inclinaría por el fanatismo frente al humanitarismo:

Le fanatisme, quoique sanguinaire et crüel, est pourtant une passion grande et forte qui élève le coeur de l'homme, qui lui fait mépriser la mort, qui lui donne un ressort prodigieux et qu'il ne faut que mieux diriger pour en tirer les plus sublimes vertus. ${ }^{143}$

Así, ante la disyuntiva de formar hombres o ciudadanos, Rousseau elige formar ciudadanos ${ }^{144}$ para que aprendan a "se chérir mutuellement comme des freres, à ne vouloir jamais que ce que veut la société» ${ }^{145}$ y a vivir y morir por la patria. ${ }^{146}$ Tal es el juramento que exige a los corsos para obtener la ciudadanía:

Au nom de Dieu tout puissant et sur les saints Evangiles par un serment sacré et irrevocable je m'unis de corps, de biens, de volonté et de toute ma puissance à la nation corse pour lui appartenir en toute proprieté, moi et tout ce qui dépend de moi. Je jure de vivre et mourir pour elle. ${ }^{147}$

Pero impulsar el patriotismo requiere, además de una religión y de una educación cívicas que preserven a toda costa la identidad del grupo, la exclusión: "Tout patriote est dur aux étrangers; ils ne sont qu'hommes, ils ne sont rien à ses yeux». ${ }^{148}$ Ese patriotismo excluyente, que levanta barreras entre los pueblos y combate los lazos de fraternidad universal, que restringe la solidaridad humana a los límites del propio grupo, y que raya en la xenofobia, ¿no comporta un considerable grado de intolerancia?

Ciertamente, el ideal político de Rousseau encierra un importante elemento de coacción:

A Genes on lit au devant des prisons et sur les fers des galériens ce mot Libertas. Cette application de la devise est belle et juste. En effet il n'y a que les malfaiteurs de tous états qui empêchent le Citoyen d'être libre. Dans un pays où tous ces gens-là seroient aux Galeres, on jouiroit de la plus parfaite liberté. ${ }^{149}$

\footnotetext{
140 Ibídem: 706, nota.

141 Abbé Bergier 1771: II, 156.

142 Ibídem: I, 78.

143 Rousseau 1969a: 632-33, nota. citoyens». Rousseau 1964: 259.

145 Ibídem: 261. Subrayado mío.

146 ídem.

147 Rousseau 1964: 943

148 Rousseau 1969a: 248.

149 Rousseau 1964: 440, nota.
}

144 «La patrie ne peut subsister sans la liberté, ni la liberté sans la vertu, ni la vertu sans les citoyesns; vous aurez tout si vous formez des
El recurso a la coacción por parte de Rousseau se explica por la necesidad de vencer las pasiones, el egoísmo y el amor propio de los hombres ${ }^{150}$, y conducirles hacia la virtud. Al partir de la dualidad cuerpo alma de origen platónico, que retoman San Agustín, los Reformadores o Descartes, Rousseau se ve en la necesidad de recurrir a la coerción para «renaturalizar» ${ }^{151}$ a los seres humanos y convertirlos en seres aptos para la vida social, es decir, en ciudadanos:

Les particuliers voyent le bien qu'ils rejettent: le public veut le bien qu'il ne voit pas. Tous ont également besoin de guides: Il faut obliger les uns à conformer leurs volontés à leur raison; il faut apprendre à l'autre a connoitre ce qu'il veut. ${ }^{152}$

De ahí que tenga que recurrir a la fuerza del Estado porque la lucha que lleva a cabo cada individuo en su interior entre su voluntad individual y su voluntad general no siempre se salda positivamente. ${ }^{153}$ Pero en realidad no solamente se trata de mantener a raya los intereses individuales, sino que ni siquiera la propia colectividad soberana es de fiar. ${ }^{154}$ ¿Cómo podría una multitud ciega que con frecuencia no sabe lo que quiere y que tampoco sabe dónde está el bien, llevar a cabo una empresa tan grande como es la legislación? ${ }^{155}$

De ahí también su apuesta por un poder absoluto, sagrado e inviolable ${ }^{156}$, que mantenga en jaque los intereses individuales $y$, como consecuencia, la ausencia de límites constitucionales ${ }^{157}$ y de cualquier otro tipo de freno legal.

Pero no solo el sistema político de Rousseau se yergue sobre la coacción («quiconque refusera d'obéir à la volonté générale y sera contraint par tout le corps: ce qui ne signifie autre chose sinon qu'on le forcera d'être libre») $)^{158}$. También su modelo educativo se erige sobre una obediencia disfrazada de libertad («prenez une route opposée avec vôtre élêve; qu'il croye toujours être le maitre et que ce soit toujours vous qui le soyez. II n'y a point d'assujetissement si parfait que celui qui garde l'apparence de la liberté; on captive ainsi la liberté même»). ${ }^{159}$ Asimismo su religión natural, esconde, como hemos visto, bajo la apariencia de la tolerancia, fuertes dosis de intransigencia. Por ello podríamos concluir que Rousseau, uno de los supuestos paladines de la tolerancia, es más intolerante de lo que a primera vista aparenta, y ello a pesar de las solemnes declaraciones a favor de la libertad religiosa que salpican sus escritos.

150 Males, que una sociabilidad nefasta ha engendrado al impulsar la perfectibilidad, cualidad latente en el hombre natural que desarrolla junto con la razón y la reflexión, el amor propio, y es la «source de tous les malheurs de l'homme». Rousseau 1964: 142.

151 «Celui qui ose entreprendre d'instituer un peuple doit se sentir en état de changer, pour ainsi dire, la nature humaine; de transformer chaque individu, qui par lui-même est un tout parfait et solitaire, en partie d'un plus grand tout dont cet individu reçoive en quelque sorte sa vie et son être». Rousseau 1964: 381.

152 Ibídem: 380.

153 Ídem.

154 «Il faut des arts, des Loix, des Gouvernemens aux Peuples comme il faut des béquilles aux vieillards». Rousseau 1964: 232

155 Ibídem: 380.

156 Ibídem: 375.

157 «Il n'y a dans l'Etat aucune loi fondamentale qui ne se puisse révoquer, non pas même le pacte social». Rousseau 1964: 436.

158 Ibídem: 364.

159 Rousseau 1969a: 362. 


\section{BiBLIOGRAFÍA}

Abbé Bergier. 1771. Le déisme réfuté par lui-même. Paris: Chez Humblot. II vols.

Cassirer, E. 1975. Filosofía de la llustración. México: F. C. E.

Charles, S. 2008. «De Popkin à Rousseau: retour sur le scepticisme des Lumières». Revue philosophiques 35 (1): 278-284.

Fabre, J. 1961. "Deux frères ennemis: Diderot et Jean-Jacques». Diderot Studies 3: 155-215.

Hobbes, T. 1983. Leviatán. Madrid: Editora Nacional.

Hunter, I. 2011. "Libertad religiosa y coacción racional. Thomasius y Locke sobre la tolerancia», en M. J. Villaverde y J. C. Laursen (eds.), Forjadores de la tolerancia: 138-139. Madrid: Tecnos.

Jedryka, Z. 1973. "L'usage politique du 'Dogme Socinien' (Liberté de Conscience) au XVIIIe. siècle», en Actes du Colloque Internationa des Lumières de Lille: 29.

Maquiavelo, N. 2003. Discursos sobre la primera década de Tito Livio. Madrid: Alianza.

Pufendorf, S. 1732. Le Droit de la Nature et des Gens, ou Système Generale des Principes les plus importants de la Morale, de la Jurisprudence et de la Politique. Thourneisen: Freres. [Edit. E. \& J. R.].

Rousseau, J. J. 1961. Oeuvres complètes II. La Nouvelle Héloïse. Mélanges de Littérature et de morale. Pensées d'un esprit droit et sentimens d'un coeur vertueux. Paris: Gallimard.

Rousseau, J. J. 1964. Oeuvres complètes III. Discours sur l'Origine et les Fondemens de l'Inégalité parmi les hommes. Discours sur I'Economie politique. Du Contract social. Lettres écrites de la Montagne. Considérations sur le Gouvernement de Pologne et sur sa Réformation projettée. Projet de Constitution pour la Corse. Fragments séparés. Lettre à M. Philopolis. Paris: Gallimard.

Rousseau, J. J. 1967a. Oeuvres complètes I. Oeuvres autobiographiques. Les Rêveries du promeneur solitaire. Paris: Seuil.

Rousseau, J. J. 1967b. Lettre à d'Alembert sur son article Genève. Paris: Garnier-Flammarion.

Rousseau, J. J. 1969a. Oeuvres complètes IV. Emile. Lettre à Christophe de Beaumont. Fragments de la Lettre à $\mathrm{C}$. de Beaumont. Lettres morales. Lettre à M. de Franquières. Lettre à Voltaire. Notes sur 'De I'Esprit'. Paris: Gallimard.

Rousseau, J. J. 1969b. Correspondance complète de Jean-Jacques Rousseau VIII y XXIX. Edition critique établie et annotée par R. A. Leigh. Lettre à Mme. la marquise de Créqui du 5 février 1761. Lettre au Chevalier d'Eon du 31 de mars 1766. Genève: Publications de I'Institut et Musée Voltaire.

Rousseau, J. J. 1974. Lettres Philosophiques. Paris: Vrin. [Note responsive à M. de Malesherbes].

Rousseau, J. J. 1988. El contrato social o Principios de derecho político. Madrid: Tecnos. [Estudio preliminar y traducción de M.a J. Villaverde].

Spinoza, B. 1986. Tratado Teológico-Político. Madrid: Alianza.

Vernière, P. 1954. Spinoza et la pensée française avant la Révolution. Paris: PUF.

Villaverde, M.a J. 1999. «Rousseau, lecteur de Spinoza», en T. L'Aminot (ed.), Jean-Jacques Rousseau et la lectura: 117-139. Oxford: Voltaire Foundation.

Villaverde, M. a J. 2001. «Trois concepts-clé dans la pensé du citoyen de Genève: Patrie, Cité, Nation", en AA. VV., Jean-Jacques Rousseau, Politique et Nation: 14. Paris: Honoré Champion.

Villaverde, M.a J. 2010-2011. "Rousseau ou la fausse tolérance», en C. Labro y T. L'Aminot (eds.), Rugosité de Rousseau: 347-348. Montmorency: SIAM-JJR.

Villaverde, M.a J. 2011. «Intolerancia, coacción y fanatismo en un apóstol de la tolerancia: Rousseau», en M. J. Villaverde y J. C. Laursen (eds.), Forjadores de la tolerancia: 257-258. Madrid: Tecnos

Villaverde, M.a J. 2012. "Spinoza's Paradoxes», en M.a J. Villaverde y J. C. Laursen (eds.), Paradoxes of Religious Toleration in Early Modern Political Thought: 31. Lanham, Maryland; Plymouth, United Kingdom: Lexington Books.

Villaverde, M.a J. 2015. "Rousseau: Philosophical and Religious Skepticism», en J. C. Laursen y G. Paganini (eds.), Skepticism and Political Thought inn the Seventeenth and Eighteenth Centuries: 211. Toronto: The University of Andrews Clark Memorial Library. 